\title{
1 \\ LA DIVERSIFICACIÓN DE ACTORES SOCIALES EN LA PROVISIÓN DE BIENES PÚBLICOS EN CHILE. SUS IMPLICACIONES PARA LAS POLİTICAS SOCIALES EN AMÉRICA LATINA
}

\author{
Nuria Cunill-Grau ( \\ CEDER / Universidad de Los Lagos (Chile) \\ Jeanne W. Simon ${ }^{(\cdot)}$ \\ Universidad de Concepción (Chile) \\ Cristian Leyton (*) \\ Centro Latinoamericano \\ para el Desarrollo Rural
}

\section{RESUMEN}

Este estudio aporta al debate en torno a la relación Estado-sociedad en el desarrollo social proponiendo una tipología teórica de actores privados involucrados en la provisión de bienes y servicios públicos que permita derivar lecciones de políticas. La tipología propuesta se contrasta empíricamente con una muestra de organizaciones no gubernamentales de Chile. Los resultados evidencian una multiplicidad de organizaciones sin fines de lucro (OSFL) como también de las denominadas «empresas sociales" y muestran varios nudos críticos sobre el financiamiento de servicios sociales. El artículo concluye que en América Latina existe un importante margen de acción para crear condiciones habilitadoras a las empresas sociales que enfatizan en la solidaridad y el capital relacional. Los resultados también sugieren que un financiamiento público insuficiente e inestable puede arriesgar los propósitos y autonomía política-social de las OSFL tanto como que el Estado actúe como garante de derechos.

\section{PALABRAS CLAVE:}

Organizaciones no gubernamentales, Empresas Sociales, Política Social, Cooperación Público-Privada, América Latina

RECEPCIÓN: 06/11/16

ACEPTACIŌN FINAL: 14/03/17
(•.)E-mail: jsimon@udec.cl

(‥) E-mail: cleyton@rimisp.org 